\title{
Menores en el campo migratorio transnacional. Los niños del centro (Drari d'sentro)
}

\author{
Liliana Suárez-Navaz \\ Mercedes Jiménez Álvarez \\ Departamento de Antropología Social. Universidad Autónoma de Madrid \\ liliana.suarez@uam.es \\ tangermeme@hotmail.com
}

Recibido: 30-03-2008

Aceptado: 04-03-2009

\section{Resumen}

El artículo analiza el estudio de caso de «menores no acompañados» de Marruecos para mostrar cómo ha prevalecido, tanto en la investigación académica como en la gestión política, una concepción de los menores que migran sólos que no incorpora la agencia como sujetos que su novilidad a través de las fronteras manifiesta, generando una deficiente e ineficaz construcción de los mismos bien como víctimas o como criminales. A partir de una propuesta teórica y metodológica que conceptualiza estos menores como nuevos actores migratorios, el trabajo presenta los resultados de la investigación sobre sus vínculos familiares, las relaciones con sus padres, y sus procesos migratorios como configurados a través de una tensa relación entre la Ley de Extranjería y la Ley de Protección del Menor. El artículo se basa en el trabajo de campo realizado en España y Marruecos, y muestra el modo en que los estados involucrados manipulan la dependencia y/o autonomía de estos menores a través de acuerdos políticos, creando una tendencia de exclusión creciente de estos menores de un sistema de protección en el país receptor del que ellos se reivindican como titulares.

Palabras clave: menores migrantes; transnacionalismo; juventud; pobreza; exclusión; movilidad.

\section{Abstract. Minors in the transnacional migratory field (Drari d'sentro)}

The article analyzes the study case of «Non Accompanied Minors» from Morocco to show how a conception of minors who migrate alone without actively incorporating their agency as subject crossing international borders, precludes a correct and efficient work in both academic research and policies which informs dominant conceptions of them as wither victims or criminals. A new theoretical and methodological proposal of these minors as new migratory actors thus informs the findings of our research on their familial networks, the relations with their parents, and their migratory processes as shaped by a strained articulation of Alien Law and Minor Protection Law. The article is based on fieldwork in Spain and Morocco, and shows how the States involved manipulate minors' dependency or autonomy through political agreements creating an even-increasing exclusionary tendency of minors from the protection system they are claiming to be entitled to.

Keywords: minor migrants; transnationalism; youth; poverty; exclusion; mobility. 


\section{Sumario}

Marco conceptual sobre menores y familias: sobre definiciones, titularidad y derechos

Familia, pobreza y menores migrantes desde Marruecos

Los menores migrantes como nuevos actores migratorios
La construcción normativa y política de los menores migrantes en el campo migratorio transnacional

Repatriaciones y devoluciones de menores y externalización de la obligación de proteger a la infancia

A modo de conclusión

Referencias bibliográficas

La migración de menores y jóvenes ha sido tradicionalmente entendida como parte de una estrategia familiar, y su protagonismo, por lo general, subsumido en ésta. Diferentes investigaciones han comenzado a prestar más atención a los menores en los procesos migratorios. Whitehead y Hashim (2005: 11), en su estudio Children and Migration, constatan que el número de menores afectados por los flujos migratorios contemporáneos es cada vez más alto, aunque difícilmente cuantificable. Su investigación distingue tres situaciones en las que se encuentran estos menores: los menores que "son dejados atrás" cuando emigra el padre, la madre o ambos progenitores; los menores que migran con sus familias, y los menores que migran ellos mismos de forma independiente de sus familias. En un relevante trabajo de recopilación y revisión de bibliografía de familias transnacionales, Le Gall subraya la idea de que los niños participan de forma activa en los procesos de migración transnacional de sus familias (2005:34). Por otro lado, Orellana analiza cómo se entrelazan las «necesidades» y las «capacidades» de estos menores (según su edad y su género) y cómo pueden llegar a ser "puntos centrales» en las estrategias migratorias de sus familias (2001: 573).

Sin embargo, en este artículo queremos ir más allá y centrarnos en un tipo de migración juvenil que no puede comprenderse sólo en el contexto familiar. Se trata de menores que se desplazan a través de las fronteras internacionales como resultado de una decisión autónoma ${ }^{1}$, algo cada vez más frecuente. Éste es un

1. Aunque más adelante se verá claramente, es necesario aquí precisar que, cuando decimos «autónoma», no excluimos que la decisión de cruzar fronteras sea conocida o compartida por la familia. Whitehead y Hashim (2005: 25) señalan que las distintas investigaciones llevadas a cabo con menores que migran de forma autónoma los enmarcan en seis categorías: menores que migran para trabajar o estudiar, menores que son víctimas de una red de tráfico, menores en acogida, menores refugiados y demandantes de asilo, los que se han visto forzados a migrar y los menores huérfanos, principalmente por el fallecimiento de sus padres a causa del sida. Como en el caso de la migración de las mujeres, lo importante no es que la decisión de migrar sea consensuada con los miembros de la familia y en especial por el varón cónyuge - en el caso de que sea la mujer la que inicie la cadena migratoria. Lo importante en este caso, como ha demostrado la literatura al respecto, es que la mujer toma la decisión teniendo en cuenta una serie de cuestiones que le atañen a ella específicamente (violencia de género, pobreza del encuentro conyugal, etc.), con recursos propios e intransferibles y con objetivos distinguibles de otros miembros de la unidad familiar (ver Suárez Navaz, 2004b, 2006). 
fenómeno inquietante en un doble sentido. Primero, porque la especial vulnerabilidad de niños cruzando las poderosas fronteras entre países y continentes es evidente. Segundo, porque su capacidad para navegar entre los intersticios de las contradicciones de nuestra sociedad occidental es manifiesta, y, aunque patética y peligrosa, forma parte de sus estrategias de resistencia.

Sin ignorar la importancia de la familia en la socialización del menor y en sus patrones migratorios, este trabajo desplaza la atención analítica al estudio de la construcción politica del vínculo familiar en un campo migratorio transnacional. Partimos de la premisa de que los jóvenes que migran solos deben ser considerados nuevos actores migratorios, cuyas estrategias de movilidad transnacional responden a su posición especialmente vulnerable y frustrante (Suárez Navaz, 2006). Nuestra hipótesis de trabajo plantea que estas migraciones están sacudiendo el concepto de responsabilidad de la infancia. Los estados involucrados en la migración de los menores son conscientes del reto que implica. Durante los últimos años, se han involucrado en la creación de nuevas estrategias jurídico-políticas cuyo objetivo central es redefinir al menor migrante y, consecuentemente, su responsabilidad estatal como tutores de los mismos. Estas estrategias demuestran no sólo que, hoy por hoy, prevalece la lógica de la seguridad sobre la lógica de la protección, sino también que las razones por las cuales se excluye del colectivo de menores en la migración a los que migran solos es consecuencia de una construcción política e ideológica, ajena tanto a la lógica científica que debe regir nuestros análisis, como a los derechos humanos reconocidos a los menores.

De hecho, es atípico que un trabajo sobre menores que han migrado solos (o menores no acompañados) figure en una compilación sobre jóvenes hijos de inmigrantes como la que se propone para este número monográfico. Como veremos, esta tradicional ausencia es del todo significativa. Por una parte, estos jóvenes escapan de las definiciones que pretenden atrapar sus itinerarios en un contexto familiar. Por otra, estos jóvenes están situados en una posición liminal respecto a nuestras definiciones de niñez y juventud, marcadas por la dependencia. Y, finalmente, estos jóvenes son los menos deseados entre los inmigrantes: no se incorporan a nuestras estructuras de socialización de manera estable e inequívoca, sino como parte de trayectorias no lineales y, en ocasiones, frustrantes para los profesionales que invierten esfuerzo en su inserción social en España. En torno a estos menores, se produce una construcción como colectivo "criminalizado», "escurridizo" y altamente peligroso que se "aprovecha» de los sistemas públicos de protección de la infancia y «burla» la lógica de la protección establecida para los menores autóctonos. Son menores que supuestamente «no quieren ser protegidos» y se les culpabiliza de «asumir un papel de mayores de edad», hasta el punto de desdibujar su condición de menores por entenderlos «emancipados» por el hecho de emigrar, como vemos en este trabajo ${ }^{2}$.

Nuestro interés es mostrar, a través de la investigación realizada en el campo migratorio transnacional que une Marruecos y España desde el año 2000, el

2. Instrucción del fiscal general del Estado. 
tipo de estrategias de movilidad internacional puestas en marcha por estos jóvenes, estrategias que provocan y cuestionan las fronteras marcadas por las políticas migratorias y por el sentido común burgués que las domina. Analizaremos las respuestas estatales de los países involucrados en el campo transnacional a través del cual se producen las migraciones de los menores, mostrando la articulación entre las nuevas directrices y estrategias políticas, por una parte, y las respuestas de los menores, por otra, la pieza más vulnerable de este complejo puzzle. Dada la relevancia analítica y experiencial de las familias en este campo de estudio, veremos cómo este nuevo sujeto migratorio combina los vínculos con las distancias familiares. Nuevas combinaciones de dependencias y autonomías hacen necesario reformular los vínculos entre los menores y sus familias y, por tanto, reformular las premisas usualmente implícitas en la consideración del menor como tal sujeto jurídico y sociológico. La hipótesis de fondo no se limita a resaltar el carácter agencial y delinear la particularidad de los menores como nuevos actores migratorios (Suárez Navaz, 2006), sino mostrar el modo en que la propia categoría de menores y de su vinculación familiar es un campo de batalla configurado por las relaciones de poder propias del campo social transnacional entre Marruecos y España, como uno de los nudos más complejos del Mediterráneo occidental.

\section{Marco conceptual sobre menores y familias: sobre definiciones, titularidad y derechos}

Una piedra angular en la definición de la minoría de edad es el vínculo de dependencia respecto a familiares adultos comprometidos socialmente con su cuidado. Sabemos que ésta no es una definición transcultural ni históricamente universal, como nos han demostrado los numerosos estudios en la materia (ver Feixa, 1999, para una excelente inmersión en sus fundamentos). Pero, como en demasiadas ocasiones sucede, los avances teóricos no son transversalmente aplicados en todas las temáticas relacionadas. Este es el caso de los jóvenes vinculados a los procesos migratorios y, muy especialmente, los que migran solos. El contexto analítico que estudia los menores en la migración en nuestro entorno académico apenas ha explorado la relación entre los jóvenes y sus familias en los procesos migratorios (con algunas excepciones en los trabajos de Terren, García Borrego, etc.). A pesar de ello, creemos no errar al afirmar que a todo menor se le supone una dependencia del cuidado de miembros adultos de su familia. Es, por tanto, una premisa epistemológica tácita, si bien no desarrollada metodológica y teóricamente en todos los trabajos sobre menores hijos de inmigrantes en España.

Por otra parte, y yendo más allá de la cuestión analítica para abordar la dimensión normativa y política, el menor es un sujeto jurídico dependiente por definición, a pesar de las doctrinas más progresistas que le reconocen una capacidad de obrar progresiva. Sin duda, compartimos la importancia de la protección parental para el idóneo desarrollo de los niños. El menor tiene derecho a tener una familia, como regula la normativa de protección del menor. Ahora 
bien, no podemos tampoco negar que es posible, en ocasiones incluso deseable, librarse de una mala influencia parental o bien que las circunstancias de la vida hacen que esta protección sea del todo insuficiente. Nuestra normativa así lo reconoce: el interés último del menor ha de prevalecer frente a la paternidad biológica, y el Estado se hace responsable como garante de esos derechos esenciales de los menores en ausencia de adultos responsables vinculados a través de parentesco (nuclear o extenso). Lo que de común mantienen ambos horizontes normativos es el carácter beneficioso de la protección del menor, y es secundario quién ejerza la protección. De la necesaria e ideal protección, no obstante, no se deduce que aquél no pueda desarrollarse de manera autónoma.

Que los menores han sido responsables de su destino desde siempre lo atestigua la producción literaria clásica picaresca del tipo del Lazarillo de Tormes e innumerables otros testimonios artísticos o autobiográficos. La idea de que la familia es responsable de la educación y promoción de los hijos nace con la Ilustración, porque hasta entonces el menor tiene una mayor independencia, como ha mostrado Feixa (1999). Con la expansión de la modernidad, se naturaliza la dependencia del menor tanto como la consecución de la independencia que se adquiere en un periodo adulto. Lo que es peor, la falta de un cuidado parental, más que una circunstancia penosa pero superable, se convierte en explicación de patologías psicológicas o sociales (la melancolía, por ejemplo, o la disfuncionalidad social), con lo cual se esencializa lo que es resultado de dinámicas socioeconómicas concretas.

La ideología de la familia, con todo y no ser universal, tiene una constante efectividad simbólica. La teoría feminista desempacó las desigualdades y las tensiones de género consustanciales a la reproducción de la ideología de la familia patriarcal, desvelando como inapropiado el uso acrítico de la familia como unidad analítica. La perspectiva de género inoculó una complejidad en la unidad familiar en la que surgieron no sólo desigualdades, sino también efectos diferenciados de procesos socioeconómicos en hombres y mujeres. Respecto a los menores, no existe el activismo ni el pensamiento teórico asociado al feminismo. La desigualdad entre menores y adultos se ha descrito como estructural, pero superable eventualmente, como Meillasoux analizó. Pero la piedra angular de esta superabilidad está en mantener las estructuras sociales que permiten los ritos de paso, la iniciación a la vida adulta y, especialmente en el caso de los varones, la independencia a través del trabajo y el matrimonio.

En otros lugares, hemos profundizado sobre las condiciones estructurales, asociadas al postfordismo neoliberal, que hacen difícil la iniciación a la vida adulta a través de los canales tradicionales, como la obtención de un trabajo estable, el matrimonio o la adquisición de vivienda. Los jóvenes que hemos estudiado no tienen una familia agrupada residencialmente, con madres dedicadas amorosamente a la crianza y padres esforzados en traer un magro sueldo a casa. Estos jóvenes y la cultura postcolonial que habitan está marcada por la exclusión, como veremos a continuación mediante el dibujo etnográfico del entorno de ciudades fronterizas como Tánger y el interior marroquí: exclusión de espacios locales amables, de escuelas formativas, de familias acogedo- 
ras. No son palabras sólo, son realidades marcadas por la pobreza y las carencias habitacionales, la inexistencia de políticas públicas, la lejana y siempre distante relación entre los ciudadanos del Tercer Mundo y sus corruptos estados. Estos jóvenes que no encajan con nuestra utópica imagen de miembros de una familia, están resignificando sus vínculos y construyendo estrategias de resistencia a través de prácticas variadas, entre las cuales nos encontramos las migraciones internacionales.

Así pues, estos jóvenes migrantes son un nuevo actor social también en su relación con la familia y con el estado. Mientras que los jóvenes postindustriales que define Feixa (1999: 43 y s.) como el más reciente tipo ideal de juventud, se ven favorecidos por la expansión del Estado de bienestar y «se convierten en uno de los sectores más beneficiados por las políticas de bienestar, ansiosas de mostrar sus éxitos en las nuevas generaciones», estos menores que migran solos ni se han beneficiado de una familia protectora ni ningún estado quiere realmente hacer suya esta responsabilidad normativa y sociopolítica. La crisis de la autoridad paterna se describe como otro de los rasgos idiosincrásicos del joven postindustrial, cuando, en el caso de los menores migrantes, esa autoridad no se quiebra por una «revuelta contra todas las formas de autoritarismo", sino por el efecto del capitalismo neoliberal en las estructuras familiares de áreas pobres del planeta. Así queda patente que la definición de joven postindustrial usada por Feixa adolezca de cierto etnocentrismo involuntario, pues, al introducir los jóvenes migrantes, se hacen patentes sus límites. Finalmente, estos jóvenes migrantes no desarrollan su subcultura o sus estrategias de resistencia a través de la territorialidad, sino, por el contrario, a través de la desterritorialización de sus ritos y rutas juveniles.

Aunque necesitamos más investigación empírica comparada a nivel internacional y una mayor perspectiva histórica, planteamos a través de esta nueva propuesta teórica y metodológica la necesidad de reflexionar acerca de un nuevo tipo ideal de joven postcolonial, marcado por la debilidad del Estado del bienestar, la debilidad postfordista de las estructuras que posibilitaban la iniciación a la edad adulta (trabajo y familia) y la puesta en marcha de estrategias de movilidad transnacional, así como de solidaridades desterritorializadas. En todo caso, sí tenemos suficiente información empírica para constatar que estas características coadyuvan en la formación de un nuevo tipo de actor migratorio cuyo rasgo distintivo es su minoría de edad. Veamos algunos rasgos interesantes que definen a este nuevo actor migratorio a través del ejemplo de los niños y los jóvenes marroquíes en España.

\section{Familia, pobreza y menores migrantes desde Marruecos}

En Marruecos, la migración de menores se inscribe en un contexto donde entran en juego factores sociodemográficos, políticos, sociales, jurídicos y económicos que condicionan la aparición de contextos de exclusión en los que viven la mayor parte de las familias de estos jóvenes y donde los derechos de las mujeres y de los menores son especialmente vulnerados, sin que exista una admi- 
nistración pública garante de estos derechos con mecanismos efectivos para salvaguardarlos. La mayor parte de las familias de estos menores vive en contextos de exclusión, riesgo y desvinculación social, tanto en zonas urbanas como rurales. Podemos señalar dos contextos principales de procedencia de los menores marroquíes que llegan a España: contextos urbanos y contextos rurales ${ }^{3}$ :

La región Tánger-Tetuán es una de las principales zonas de origen de estos menores. Los jóvenes que migran de esta región proceden principalmente de ciudades y del extrarradio de los principales núcleos urbanos, aunque no exclusivamente, ya que se da la migración de menores originarios de las zonas rurales de esta región. De forma muy simplificada, podemos señalar que, en estos contextos urbanos, no existe una «estrategia familiar» como tal, es decir, de forma mayoritaria, la familia no sufraga los gastos de la migración y programa con el hijo su migración. Los menores llegan a España cruzando por el puerto de Tánger o por la frontera del Tarahal con Ceuta. No existen intermediarios a los que pagar, los menores migran de forma autónoma y se apoyan principalmente en sus redes de iguales. Es cierto que, de forma excepcional, sí que hemos encontrado familias que sufragan los gastos de la migración de sus hijos mediante mecanismos más mediatizados como la compra de visados, pero es algo excepcional.

La segunda zona a la que nos vamos a referir es la formada por las regiones Tadla-Azilal, Chaouia-Ouardigha y Marrakech-Tensift-Al Haouz, pero, en concreto, nos interesan las ciudades y los duares (pueblos) en torno a Kelaa des Sragna, Beni Mellal y Boujad. A partir del año 2003, se generaliza la llegada en patera de menores procedentes de estas zonas. Su presencia en las pateras nos obliga a hablar de estrategias familiares. Es en las zonas rurales donde el papel que la familia tiene a la hora de apoyar la migración de los menores puede llegar a ser central. Esto se plasma en que es la familia, nuclear o extensa, la que busca los recursos para pagar el viaje del joven. Su migración se inscribe en un contexto familiar más amplio, donde hay una elaboración previa sobre las posibles oportunidades que dará la migración y cierta planificación.

Pero, como suele suceder, esta clara tipología viene a complicarse por diversos procesos que inciden en los flujos migratorios. La creación de un campo migratorio transnacional se concreta a nivel local con la apertura o la profundización de circuitos migratorios que articulan rutas nacionales e internacionales. Señalaremos dos ejemplos interesantes. En primer lugar, se da la variante de que menores del interior rural llegan a zonas fronterizas (Tánger, Casablanca, Nador) para intentar la migración internacional. En general, estos son menores que proceden de familias tan sumamente pobres que no pueden costear la migración del hijo, o bien de familias rotas, donde el menor vive una clara situación de abandono. En segundo lugar, hemos de destacar el modo en que, a partir del año 2004, la aplicación de la Instrucción 3/2003 — que permitía

3. Aunque comienzan también a destacar otra regiones, como Alhucemas-Taza-Taounate, la Oriental, Meknes-Tafilalet (Errachidía) y Casablanca. 
el retorno en frontera de los menores mayores de dieciséis años (mayoritariamente procedentes de zonas rurales) - provocó que, una vez expulsados, estos menores intentaran una segunda migración desde una zona fronteriza (Tánger, Nador, Castillejos). Como veremos más adelante, las malas actuaciones de las políticas de devolución provoca no sólo situaciones de desamparo efectivo en zona marginal urbana, pues los menores del interior devueltos no pueden volver a casa por sus medios. Además, se refuerza la figura del menor que migra solo, sin apoyo familiar, con lo cual se generaliza la presencia de menores del interior de Marruecos en las zonas fronterizas, principalmente en Tánger.

Señala Bargach que los menores migrantes marroquíes están caracterizados por una doble pertenencia.

Por un lado, la pertenencia al sistema social de procedencia, donde el menor inició una socialización en el seno de un sistema familiar [...] el menor, aún distanciado físicamente de su sistema social de procedencia, mantiene un apego fuerte, manifestado por la intensidad de los afectos y por el sistema de lealtades hacia su sistema sociofamiliar de procedencia [...]. [E] segundo aspecto se centra en el sistema social receptor donde el menor está ubicado, que cumple la tarea de completar su socialización y emancipación, y donde busca construir un proyecto de vida que le ha sido denegado en el país de procedencia. Este menor está necesitado de una confirmación social, tanto en un sistema como en el otro. [...] [J]ustamente en esta doble y compleja pertenencia deriva la originalidad y la especificidad de estos menores. Al mismo tiempo y con asombro, pensamos que de esta complejidad de pertenencias se deriva paradójicamente la incomprensión de la que son objeto estos menores por parte de adultos, que se supone deben ser sus protectores y cuidadores (2008:2)

Existe un amplio espectro de situaciones familiares de referencia que hemos estudiando sistemáticamente en una investigación sobre contextos familiares en Marruecos ${ }^{4}$. La clasificación que propusimos a partir de este trabajo no sólo sigue aún vigente, sino que ha conseguido un alto grado de consenso y se ha usado frecuentemente en el diseño de políticas públicas, así como de investigaciones sobre los menores no acompañados ${ }^{5}$. Son cuatro las situaciones familiares de referencia de estos menores migrantes, sabiendo que no son modelos «estáticos» de hogar y que dicha clasificación sólo pretende establecer un primer acercamiento a la complejidad de la familia en Marruecos:

- Una primera situación en la que la familia se encuentra en un contexto social normalizado, los menores están escolarizados, viven con su familia

4. Mercedes Jiménez Álvarez (2003), Buscarse la vida: Análisis transnacional de los procesos migratorios de los menores marroquies no acompañados en Andalucía, Madrid, Fundación Santa María, p. 45, y «Menores inmigrantes o los vulnerables de la globalización», en: F. Checa Olmos, Á. Arjona y J.C. Checa Olmos (eds.), Menores tras la frontera. Otra inmigración que aguarda, Barcelona, Icaria Antrazyt, 2006, p. 70.

5. Utilizada por Unicef en su estudio Nouveau visage de la migration, les mineurs non accompagnés, 2005, p. 45. 
en un ambiente estable y sus miembros gozan de una situación económica que cubre las necesidades básicas, como alimento, ropa, vivienda, educación y sanidad. Es una situación minoritaria.

- Una segunda situación donde los menores viven en un ambiente familiar afectivamente estable, existe una familia nuclear y/o extensa que otorga equilibrio afectivo. La familia vive en un contexto de exclusión social precario o muy precario, es decir, que puede llegar a no cubrir las necesidades básicas. Los menores tienen problemas en su escolarización y han podido vivir alguna primera experiencia laboral, la mayoría de las veces muy desalentadora. Estos menores pueden pasan gran parte de su tiempo en la calle, pero no hacen de ésta un medio de vida, sino que se trata de un espacio de socialización.

- Una tercera situación donde los menores habitan en un ambiente familiar inestable y la familia vive en un contexto de exclusión precario o muy precario. La suma de ambas circunstancias es lo característico de esta tercera situación. Se dan ruptura familiar y violencia intrafamiliar. Los menores viven experiencias de maltrato y desprotección.

- Una cuarta situación donde los menores viven en la calle y no mantienen una relación asidua con su familia. Se encuentran en contextos de violencia, en situaciones muy precarias y sufren todo tipo de malos tratos y abusos. Es también una situación minoritaria.

El estudio de los modelos ideales de familias de referencia y de los vínculos que los menores que migran solos mantienen con ellas es de radical importancia para la comprensión del fenómeno y para el desarrollo de políticas adecuadas a esta cuestión tan compleja. Si la segunda y la tercera situaciones son las más comunes entre los más de doscientos casos de menores y sus familias que hemos venido siguiendo a través de entrevistas y encuentros informales durante los últimos años, es evidente que lo fundamental para definir la idiosincrasia familiar de los menores migrantes es su contexto de exclusión, no el tipo de vínculo familiar que tengan o no tengan. Es esta exclusión social la que imprime su sello en la migración de los menores no acompañados, independientemente de si la familia mantiene o no su rol afectivo y educativo. Es más, como hemos visto en el caso de los menores migrantes provenientes del interior rural marroquí, puede ser incluso parte de una estrategia familiar para entrar en el campo migratorio transnacional a través del hijo y así conseguir lo que el entorno local y nacional no provee.

Así pues, lo que tienen en común estos menores es la vivencia del impacto dramático de los planes de ajuste estructural, de la proletarización acelerada de una población de origen eminentemente rural y de las nuevas bolsas de miseria de las grandes ciudades. Las vivencias comunes en nuevos jóvenes migrantes tienen que ver con la exclusión y la marginalidad: escasos servicios públicos básicos (luz, agua, alcantarillado) y menos servicios sanitarios y educativos; familias en las que las mujeres concentran el peso del mantenimiento del hogar sin poder contar siempre con las redes de la familia extensa para criar 
a sus hijos; padres que no encuentran trabajo estable, con la autoestima socavada por la deslegitimación de su tradicional autoridad basada en su inserción laboral. Este factor tiene, a nuestro modo de ver, un profundo impacto en los hijos varones, que son mayoritariamente los que migran solos. En las sociedades musulmanas como Marruecos, es mucho mayor que en sociedades ampliamente matrilineales. Si la filiación o nassab está determinada por las reglas de la patrilinealidad, los niños nacidos de mujeres solas se sienten completamente desplazados y sólo tienen acceso a una identidad legal si un varón acepta reconocer la filiación (una mujer no puede transmitir su apellido, es el padre de ésta el que puede otorgar el nombre de familia a su nieto nacido fuera de matrimonio, si no hay oposición por parte del resto de varones en la familia) ${ }^{6}$. Finalmente, el tipo de trabajos a los que los menores pueden acceder son, en general, inestables, no cualificados y mal pagados (Jiménez, 2003: 57). Entendamos bien que estos trabajos en ninguna medida permiten que el menor sustituya a su padre o madre como proveedor, más bien se trata de pequeñas contribuciones a la economía del hogar. El hecho de que muchos menores tengan que trabajar como aprendices o en la calle con formas de autoempleo genera una fuerte sensación de frustración e impotencia.

Este entorno no tiene ya la capacidad para garantizar a los menores los mecanismos de iniciación a la edad adulta, sea a través de la propia familia o un empleo asalariado. En áreas fronterizas como la de México y Estados Unidos o Marruecos y España, la migración forma parte de un imaginario social compartido alimentado por unas redes sociales muy densas que afectan, directa o indirectamente, a casi todas las familias de determinadas zonas urbanas como las que venimos describiendo. Como dijimos hace años, «los niños y jóvenes que entran en este campo migratorio desde sus márgenes, desean activar su plena entrada en cualquier momento. La mayoría de los jóvenes simplemente no se lo plantean, bien porque estén escolarizados, bien porque sus familias les protegen, bien porque tienen cierta esperanza de «buscarse la vida» en Marruecos. Pero sí los hay que usan las redes migratorias de forma activa para potenciar su marcha» (Giménez y Suárez, 2001).

Así pues, la emigración de estos jóvenes puede cumplir la función de un rito de paso, una entrada ritual a la edad adulta, que, en este contexto de origen, se ve seriamente dificultada. Como comenta Jiménez, «El referente exitoso del menor que migra crea un efecto de considerables consecuencias [...] a través de sus pares de iguales, es decir, de menores que un día se fueron y han vuelto con papeles, se interiorizan las ventajas de poder pertenecer a la

6. Existe un fuerte estigma social hacia los menores nacidos fuera del matrimonio (son llamados «hijos del pecado»), por este motivo, si no acceden a tener un reconocimiento jurídico, se encontrarán con problemas en su escolarización y en su futura identidad legal. La consideración de hijos ilegítimos de los hijos extramatrimoniales es uno de los impedimentos principales para establecer un verdadero sistema de protección de la infancia en Marruecos. En el año 2004, se modificó el Código de la Familia y se estableció un mecanismo para reconocer a los hijos de madres solas nacidos en el periodo de noviazgo. 
categoría «menor de edad» respecto a aquellos adultos que representan para ellos la experiencia de la clandestinidad en el país de destino" (2003: 41).

Se mantiene una percepción muy negativa de la migración de los menores que no permite destacar el carácter innovador y particular de ésta ni de los propios menores como constructores activos de estrategias de supervivencia efectivas. En parte, sucede que esta migración se asimila a los flujos migratorios más amplios que unen España (y Europa) con Marruecos (y África). Destacan, en el caso de los niños y jóvenes, su vulnerabilidad y la patente violación de los derechos que los acuerdos internacionales y la normativa nacional les garantizan. Aunque es evidente la necesidad de denuncia y de apoyo a estos menores en España para que sus derechos sean salvaguardados, pensamos que es errónea su representación mayoritaria como meras víctimas del sistema. Sin bien es cierto que esta situación de nuestros niños no es en ninguna medida deseable, quisiéramos defender la idea de que estos menores están construyendo alternativas propias a la situación en la que se ven atrapados.

\section{Los menores migrantes como nuevos actores migratorios}

Los menores que migran solos configuran un nuevo actor en el panorama migratorio internacional. No estamos ante hechos aislados, ante chicos especialmente aventureros que optan por seguir el camino de sus compatriotas hacia la Europa de la riqueza. Estamos ante un nuevo tipo de agente migratorio, que sigue las trayectorias geográficas de las migraciones adultas, pero que tiene su propia dinámica y naturaleza.

Los menores migrantes están haciendo uso de sus propios recursos a la hora de emigrar, no sólo en las estrategias de entrada, sino también en las redes sociales que la sustentan, en gran medida independientes del control de los adultos. A esto añadimos la extraordinaria movilidad y el dinamismo de las redes de información y apoyo entre los menores, que si bien resulta un obstáculo para los investigadores, profesionales de atención juvenil y políticos, es parte de las estrategias de resistencia al control estatal, social y familiar que se cierne sobre su futuro. Esta red de relaciones es múltiple y está altamente desterritorializada (Glick Schiller et al., 1994). Los menores no sólo mantienen las amistades de sus pandillas en origen, sino que el tipo de vida en la calle también hace que vayan forjando otras relaciones de apoyo e incluso amistad en el curso de su itinerario migratorio. Los menores acaparan con celo la información que se transmite en la red de sus amigos sobre qué centros son los más adecuados, qué hay que decir en las declaraciones ante la policía, dónde se puede ganar dinero fácil sin compromisos excesivos, etc. Dependiendo de sus objetivos y de sus necesidades coyunturales, los jóvenes decidirán acogerse a la protección oficial y entrar en un centro de atención al menor o escaparse y ganar dinero, aunque sea sin los permisos correspondientes.

En nuestra investigación confirmamos muy rápidamente la importancia de las redes de iguales en muchos de los itinerarios de estos jóvenes. En muchas 
ocasiones, emigran en grupo, con una cuidadosa planificación que aprovecha el momento pero no improvisa, dada la obvia dificultad en cruzar estas fronteras.

Ismael relata cómo es la vida en el puerto de Tánger y cómo se prepara para cruzar:

[...] En mi barrio no hay nada, las calles están destrozadas, la basura por todos sitios [...] Mi casa está aún por terminar. Me fui a España, sí. Me escondí debajo de un camión en el puerto de Tánger. La policía te trata mal. Te pega con cuerdas en las plantas de los pies. Te quita la ropa y el dinero. Tiene perros, uno se llama Sadam, todos los chavales lo conocemos. Ellos hacen que los perros nos muerdan y nosotros les tiramos piedras. Como te pillen, estás perdido. A los chicos de fuera de Tánger, de Kelaa Srgana, de Beni Mellal, los meten en un autobús y les dicen que es para llevarlos a su casa. Pero es mentira, los dejan en mitad de la autopista. Ellos vuelven a pie o hacen autoestop [...] Una mierda, el puerto es una mierda. Mueren niños aplastados por camiones, y cada vez hay más policía. Nosotros, los de mi barrio, estamos en una parte, en Dar Baroud, allí no se acercan los otros chicos. Es como nuestro territorio. Los chicos de Beni Mellal están más abajo. No entran al puerto por el mismo sitio. Yo tardé varios meses en cruzar, tienes que saber bien cómo funciona la policía y los camiones. No creas que es fácil.

Como para otros colectivos, estas redes cumplen las tradicionales funciones de apoyo, información y reducción de los riesgos y costes del proyecto migratorio o la aventura transnacional. Igual que en otros casos de migración, las redes sociales responden a carencias y limitaciones en los recursos propios para un proyecto vital satisfactorio. En el caso de los menores, son resultado de las peculiares condiciones que condenan a los jóvenes de los barrios de aluvión que hemos descrito a la exclusión (de sus casas, de la escuela, del barrio) y a la discriminación y segregación residencial y laboral respecto a la juventud de clase media en el país de origen, tanto como en el país de destino.

Hamid nos cuenta sus dos primeras semanas en España:

Crucé por el puerto de Tánger y, una vez en Algeciras, llamé a mi primo a Valencia. Él vino a buscarme. Estuve una semana viviendo con él y unos amigos en su casa. Tenía miedo de ir a la policía para que me llevaran a un centro. Pregunté a un amigo de mi barrio que estaba en Bilbao y me dijo que desde Valencia me podían devolver a Marruecos. Así que decidí irme a Bilbao sin pasar por Madrid. Llegué a Bilbao y me llevaron a un centro en mitad de una montaña, sin ventanas. Hacía mucho frío. No me gustó nada. Allí me encontré a unos chicos de mi barrio. Decidimos irnos al día siguiente a Cuenca, porque nos dijeron unos amigos que no había repatriaciones desde Cuenca. Se lo dijimos a los educadores y nos dieron dinero para el autobús. Yo creo que ellos no querían que nos quedáramos allí. Después llegamos a Madrid, la policía nos detuvo y nos llevó a un centro muy grande. Dijimos que íbamos a Cuenca y nos dejaron marchar. Llegamos por fin a Cuenca. 
Se trata de una estrategia de supervivencia innovadora, que se pone al servicio de los objetivos específicos de los menores: conseguir los papeles en el caso de España, tener una aventura y acceder a los espacios privilegiados de los jóvenes que están al otro lado de la frontera, acceder a formas de capitalización traducibles en un consumo inmediato, etc. De forma muy especial, el acceso al espacio migratorio transnacional como protagonista incide directamente en el estatus del menor. Se trata de un rito de paso que convierte al niño en un varón adulto.

\section{La construcción normativa y política de los menores migrantes en el campo migratorio transnacional}

Cuando empezamos a trabajar sobre el tema de los «menores no acompañados» ${ }^{7}$ (MNA) hace diez años, apenas comenzaba a perfilarse su migración como un fenómeno social novedoso. Se tendía a pensar en ellos como un problema. Nosotros planteamos que esto era así porque ellos encarnan las profundas contradicciones del sistema normativo nacional: mientras que, como menor, el MNA tiene todos los derechos reconocidos por nuestra normativa; como extranjero indocumentado, el interés primordial es su expulsión (Giménez y Suárez, 2001). Estas contradicciones normativas se plasman en la vida de los menores, sujetos de protección, como lo indica la Convención de los Derechos de los Niños, y sujetos de control, como lo exige la Ley Orgánica de extranjería (ver también Suárez Navaz, 2004a).

Según la normativa vigente, los menores que han llegado a España solos están en situación de desamparo y han de ser tratados de la misma forma que un menor nacional: la única respuesta que nuestro ordenamiento prevé para cualquier menor en desamparo es la efectiva e inmediata protección de la entidad pública, que, por mandato legal, habrá de velar por el menor, tenerlo en su compañía, alimentarlo y procurarle una formación integral (Arce, 2006). España ratifica, en diciembre de 1990, la Convención de Derechos del Niño (ONU, 20 de noviembre de 1989). A nivel nacional, la Constitución ratifica, en su artículo 39, el derecho de los niños a la protección prevista en los acuerdos internacionales y se guía por la Ley Orgánica 1/1996, de 15 de enero, de protección jurídica del menor, conocida como la Ley del Menor. Esta ley obliga a hacer primar el derecho superior del niño sobre cualquier interés legítimo que pudiera concurrir y se refiere, en el artículo 10 , puntos 3 y 4 , a los niños extranjeros, reconociendo el derecho de los menores extranjeros que se

7. Resolución del Consejo de la Unión Europea de 26 de junio de 1997 relativa a los menores no acompañados nacionales de países terceros (97/C 221/03), artículo 1: «1.La presente Resolución se refiere a los menores de 18 años nacionales de países terceros que lleguen al territorio de los Estados miembros sin ir acompañados de un adulto responsable de los mismos, ya sea legalmente o con arreglo a los usos y costumbres, en tanto en cuanto no estén efectivamente bajo el cuidado de un adulto responsable de ellos [... 4. La presente Resolución se entiende sin perjuicio de las disposiciones más favorables de Derecho nacional». 
encuentren en situación de riesgo o bajo tutela o guarda de la Administración pública competente la asistencia sanitaria, la educación y demás servicios públicos, aún y cuando no residan legalmente en España, además de reconocer el derecho del menor a ser documentado.

Pero en la construcción «del menor no acompañado», la dimensión normativa de su extranjería ha estado siempre presente, porque, aunque menores, a fin de cuentas, se trata de nuevos actores migratorios, y así son tratados. Según se consolida este tipo de migración, el Estado receptor desarrolla e incrementa los presupuestos y las ayudas para programas de atención, tal y como hemos visto suceder en los últimos años en España. Pero, a la vez, el Estado se esfuerza en encontrar maneras de redefinir su responsabilidad de protección universal de la infancia. Es evidente que, moral y políticamente, no es viable hoy por hoy negar la normativa de protección al menor. Lo que se abre como una posibilidad legítima es la redefinición de los vínculos del menor con la familia y el estado de origen. La presencia de la familia en la estrategia migratoria es objeto de debate en los países de destino, porque cuestiona los principios por los que el menor debe ser acogido en un centro de protección de los sistemas autonómicos. Si hay una familia en origen, los principios rectores de la protección de la infancia internacional propugnan la vuelta al hogar como la medida más deseable, aunque por encima de este principio se sitúa el interés superior del menor.

Distintos discursos políticos tienden a idealizar a las familias para legitimar las reagrupaciones familiares y eludir así, la responsabilidad de protección transnacional e internacional de la infancia, de tal modo que entienden que los menores migrantes no están realmente en "desamparo» (en España), sino que es un "desamparo buscado», porque en la situación familiar en Marruecos no hay una desprotección afectiva, sino una desprotección socioeconómica. La consejera para la Igualdad y el Bienestar Social de la Junta de Andalucía presenta los argumentos de manera clara:

Cuando estamos hablando de menores en desprotección, que están atendidos en nuestros recursos, estamos hablando de menores que, por alguna circunstancia, sobre todo, carecen del afecto de su familia, tienen un desamparo afectivo o no pueden integrarse tampoco en su familia extensa. Cuando estamos hablando, concretamente, de los menores que están llegando en este momento, y procedentes de Marruecos en su inmensa mayoría, no estamos hablando de menores en desprotección, sino que estamos hablando de menores en una desprotección buscada. Están desprotegidos, simplemente, porque llegan solos a nuestro territorio; pero no proceden de familias desestructuradas, no proceden de familias donde haya una desprotección afectiva, sino que el problema que tienen esas familias es un problema socioeconómico ${ }^{8}$.

8. Respuesta de Micaela Navarro, consejera para la Igualdad. Junta de Andalucía. Pregunta Oral 7-06/POP-000265, relativa al Plan para Menores Extranjeros no Acompañados. Diario de Sesiones del Parlamento Andaluz. 
La familia puede llegar a desempeñar un papel importante en la gestión del proyecto migratorio, como hemos visto sucede en el perfil de los menores no acompañados que provienen del sur rural. La paradoja se plantea cuando la familia vive una situación de precariedad, exclusión social y violencia tal que no puede velar por el hijo y tolera o incluso promociona su migración. ¿¿Se trata entonces de "desprotección buscada»? Una vez explicada la situación de partida de los menores, ¿podemos afirmar que la existencia de un vínculo afectivo es incompatible con la incapacidad real de protección al menor? ¿Deja el menor de serlo y de ser legítima su búsqueda transnacional de protección y tutela por el hecho de que sus progenitores no puedan o no quieran sacarle adelante?

El testimonio de Mohamed ilustra esta situación con radical crudeza:

Tengo diecisiete años. Soy de Beni Mellal. Tengo cuatro hermanos, yo soy el tercero. Estudié cuatro años en el colegio y luego me fui a ayudar a mi padre a cuidar ovejas. Después trabajé en una tienda. Después estuve haciendo pozos durante dos años, pero era muy duro. Un amigo me enseñó el oficio de soldador. Trabajaba muchas horas al día, me pagaban 500 dirhams al mes. ¡Qué cerdo! ¡Cómo me explotaba el tío! En mi casa, mi padre estaba enfermo y teníamos que trabajar. A los quince años, pensé que en Marruecos no tenía futuro y decidí emigrar. Tenía que buscarme la vida. Mi futuro no estaba en este suelo. Aquí sólo había sufrimiento. Veía a mis padres, a mis vecinos... Yo no quería una vida así. Entonces empecé a trabajar en el campo. Necesitaba dinero para pagar una patera. Mis primos estaban en Italia y me iban a ayudar. Un día, hablé con mi padre, él no quería ni oór hablar de la migración. Al final le convencí y vendió dos ovejas. Ese verano vinieron mis primos, me dejaron además quinientos euros. Por fin había conseguido el dinero para irme. Un chico de mi pueblo me llevó a Alhucemas. Éramos un grupo de 68 mayores y 15 menores. Ese viaje fue horrible, pasé tres días en el mar. La gente se volvió loca, no comíamos ni dormíamos, todos vomitaban. Unos pensaban que podían andar sobre el mar y querían ir andando hacia un barco que pasó, como si fuera una casa sobre la tierra. Después de tres días, la tercera mañana, la Guardia Civil nos rescató. Era el mes de agosto. Llegué a Almería y la policía me dijo: «Lo siento por los menores, no hay plazas, ya no hay sitio. Sois menores pero no os podéis quedar». Nos llevaron al hospital para hacerme una radiografía. Yo no quería volver, pero me devolvieron en avión a Melilla. No me dieron ningún papel. La policía española me entregó a la policía de frontera marroquí en Beni Enzar. Vendí en móvil para poder volver a casa. Volví a mi casa, era ramadán. Veinticinco días después, volví a cruzar en patera, mi primo me dio cien euros y negocié que me dejaran cruzar otra vez. Esta vez sí lo conseguí, llegué a Motril...

\section{Repatriaciones y devoluciones de menores y externalización de la obligación de proteger a la infancia}

Así vemos como es el Estado nacional el que está reintroduciendo una definición del menor a través del énfasis en su dependencia transnacional (antes ignorada), pero no para subrayar el carácter internacional de la protección a 
la infancia, sino para limitarlo. Como vemos a continuación, son múltiples las estrategias estatales para hacer valer los vínculos biológicos transnacionales, a fin de priorizar la condición de extranjero del menor e introducir un sujeto protector transnacional en el panorama normativo. El escenario por antonomasia donde cede la tensión entre la condición del menor como tal, por una parte, y su condición de extranjero, por otra, son las repatriaciones y/o las reagrupaciones familiares. Dada la centralidad de este instrumento jurídico en la definición transnacional del menor y de su normativa, vamos a detenernos aquí en el modo en que esto se ha construido, concretamente entre Marruecos y España.

Como señala Arce (2006), la repatriación o la reagrupación no es una sanción por el hecho de haber intentado entrar o por haber entrado en territorio español. Ese intento de entrada ilegal o la entrada misma, no debe ser objeto de sanción, sino de protección, según el artículo 35 de la LO de extranjería. Por lo tanto, el retorno del menor a su país de origen a efectos de reagrupación (si es con su familia) o repatriación (si se entrega a las autoridades de su país) debería tener como fin único y primordial la salvaguardia del interés superior del menor. Esto quiere decir que, en cada caso concreto, debe estar acreditado que el interés superior del menor es el de reagruparlo con su familia o entregarlo a los servicios sociales de su país de origen.

Sin embargo, lejos de gozar de un interés garantista y protector, las reagrupaciones y repatriaciones tienen, en el 99\% de los casos, un carácter punitivo, contrario a derecho y manifiestamente ilegal, tal y como establecen las distintas sentencias dictadas al respecto por los tribunales españoles durante el año $2006^{9}$. La forma ilegal e indiscriminada en la que estas reagrupaciones se llevan a cabo está provocando una reformulación en las estrategias de los menores migrantes, que la ven como la máxima expresión de la impunidad, sobre todo por el carácter arbitrario y por el modo en que se llevan a cabo. Pero a esto volveremos en breve. Veamos primero el modo en que estas reagrupaciones se han ido configurando como el instrumento privilegiado por el Estado receptor, en este caso España, para el tratamiento de la tensión entre las dinámicas de exclusión y de inclusión del campo migratorio transnacional en el que se mueven estos menores migrantes.

El 24 de septiembre de 2003, llegó a Tarifa una patera con 21 menores, el más pequeño tenía trece años. Era la primera vez que tantos niños y adolescentes llegaban en una sola patera. Dos pateras más llegaron en octubre de 2003 con un total de 49 menores, una el 16 y otra el 29. El día 27 de ese

9. Sentencia 395/06, Derechos Fundamentales 1/06; Juzgado Contencioso Administrativo $n^{\circ} 14$ de Madrid, de 25 de septiembre de 2006. Sentencia no 296/06, Procedimiento Abreviado 261/06, Juzgado Contencioso Administrativo no 1 de Huesca, de 13 de octubre de 2006. Sentencia 269/06, Procedimiento Abreviado 136/06; Juzgado Contencioso Administrativo no 25 de Madrid, de 6 de noviembre de 2006. Sentencia 325/06, Derechos Fundamentales 384/06; Juzgado Contencioso Administrativo $n^{\circ} 1$ de Cantabria, de 27 de diciembre de 2006. 
mismo mes, el fiscal general del Estado responde a la presencia de menores en las pateras con la Instrucción $3 / 2003^{10}$, en la que se posibilita el retorno en 48 horas a los menores que tengan más de dieciséis años. Poco después, el 8 de diciembre de 2003, se celebra el Marrakech la Reunión de Alto Nivel (RAN) entre España y Marruecos, con los menores migrantes como uno de los principales protagonistas del orden del día. Se trata de firmar el memorándum que posibilita la repatriación de los menores marroquíes no acompañados que se encuentran en España (anteriormente sí se producían repatriaciones, parece que este momento el interés es crear un dispositivo legal que las agilice). Dicho acuerdo se firma el 24 de diciembre en Madrid con el anterior Gobierno del PP. La Nochebuena de aquel año se celebra no sólo el nacimiento del niño Jesús, sino también la posibilidad de expulsar legalmente a los niños Mohamed y compañía, si se nos permite esta figura retórica.

Durante el año 2004, se aplicaron ambos «instrumentos», la Instrucción 3/2003 y el memorándum. La Instrucción 3/2003 «Sobre la procedencia de extranjeros menores de edad que pretenden entrar ilegalmente en España y en quienes no concurra la situación de desamparo» excluía a los menores de origen marroquí mayores de dieciséis años de los sistemas de protección, puesto que permitía la devolución inmediata en frontera. Es decir, les impedía el acceso al sistema de protección. La instrucción sostenía que estos menores «estaban emancipados de hecho", es decir, el hecho de emigrar los convertía en «adultos» antes de tiempo. Según datos oficiales, fueron sesenta los retornos que se habían hecho por esta «vía rápida» desde Motril (Granada) ${ }^{11}$. Los menores eran devueltos mediante el mismo procedimiento que los adultos, algo contrario a la ley. La única diferencia en el trato a estos menores era la intervención del ministerio fiscal (la mayoría de veces era una intervención telefónica), que valoraba la conveniencia de la devolución sin ver al menor y calculando una edad ficticia con procedimientos deficitarios, como es la prueba oseométrica. Estos menores eran devueltos en cuarenta y ocho horas en avión de Granada a Melilla y entregados a las autoridades fronterizas marroquíes. Los menores pasaron entre uno y tres días en la comisaría y fueron abandonados a su suerte, algunos a más de mil kilómetros de sus casas, ya que una gran parte era del sur de Marruecos (Kelaa Sragna, Beni Mellal). La percepción desde la Administración andaluza (región principal en la que se llevó a cabo la aplicación de esta instrucción) fue que "está vía rápida» fue más garantista para los menores ${ }^{12}$.

La práctica más extendida por estos jóvenes fue volver a intentarlo. No en patera, porque era demasiado gravoso, sino que se desplazaron a Tánger para intentar cruzar en camión. La situación de desprotección y de riesgo, lejos de

10. La Instrucción 3/2003 se titula «Sobre la procedencia del retorno de extranjeros menores de edad que pretendan entrar ilegalmente en España y en quienes no concurra la situación jurídica de desamparo».

11. $A B C, 25$ de septiembre de 2004 .

12. El Pais, 11 de septiembre de 2004. 
disminuir, aumentó. Esto significó que la aplicación de la Instrucción redujo en Andalucía el número de menores acogidos en los centros, pero no redujo el número de menores migrantes ${ }^{13}$.

Es más, esta práctica produjo una modificación en las estrategias de los menores procedentes del interior de Marruecos, que diversificaron la forma de cruzar la frontera y se hicieron más numerosos a partir del verano de 2004 en el puerto de Tánger. La mayor presencia de menores en el puerto de Tánger provocó un aumento de las medidas represoras más vigilancia dentro del puerto, subcontratación de empresas privadas de vigilancia, mayor violencia en el trato a los menores, presencia de perros como medida disuasoria en las instalaciones del puerto y mecanismos de "limpieza» de los menores en el puerto mediante la detención y la expulsión en autobuses.

Frente a todas estas medidas que comenzaron en el año 2004, los menores han reformulado sus propias estrategias para escapar a esta férrea vigilancia. Por ejemplo, desde el verano del 2007, es frecuente ver a altas horas de la noche, durante el fin de semana, grupos de menores en el último peaje de salida de la autopista a Tánger, parada obligada de todos los camiones que van a atravesar el Estrecho y llegan cargados de mercancías desde distintos puntos del país. Ellos se esconden debajo de los remolques no ya dentro del puerto, sino en las paradas obligadas de estos camiones. La represión en el puerto está «externalizando» las estrategias de los menores, que reformulan nuevas formas de burlar el control policial de forma más rápida y flexible.

Por otro lado, el marco en el que se llevan a cabo las reagrupaciones familiares entre 2003 y 2006 es el memorándum de entendimiento entre Marruecos y España sobre repatriación asistida de menores no acompañados. En marzo de 2007, dicho memorándum se eleva a acuerdo bilateral ${ }^{14}$. Estas repatriaciones se realizan de forma indiscriminada y generan cierto recelo entre los menores a la hora de permanecer en los centros de acogida. Los principales derechos que se vulneran son el derecho a ser oído, la tutela judicial efectiva (no se les notifica la reagrupación), el análisis individualizado de cada caso y el retorno efectivo a su entorno familiar o al sistema de protección de sus países de origen. Las principales comunidades desde las que se están produciendo estas «reagrupaciones familiares» son Madrid, Cataluña, País Vasco y Cantabria, de las cuales Madrid es la comunidad desde la que se producen anualmente más reagrupaciones. Ocurre que los menores, ante la amenaza de repatriación desde estas comunidades autónomas, están desplazándose hacia otras que ellos consideran «más seguras», como vimos en sus relatos. Por un lado, la mayoría de los

13. Tras el cambio de Gobierno en marzo del 2004 y el nombramiento de un nuevo fiscal general del Estado, se anuló dicha Instrucción y se dictó la Instrucción 6/2004, de 26 de noviembre, sobre tratamiento jurídico de los menores extranjeros inmigrantes no acompañados, de corte mucho más proteccionista, en la que la Fiscalía se vuelve a posicionar, acorde con su estatuto orgánico, como supremo garante de los intereses de los menores en juicio y fuera de él.

14. «Acuerdo entre Marruecos y España sobre la cooperación en el campo de la prevención de la migración de menores marroquíes no acompañados, su protección y su reagrupación familiar». 
jóvenes que retornan a España tras ser repatriados, tienen miedo de volver al circuito de protección que les "expulsó», por lo tanto, «se buscan la vida» fuera de éste. Lo hacen a través de sus redes de iguales o de la familia cercana o extensa que les presta algún tipo de ayuda. Pero, como hemos visto, las condiciones provocan que algunos terminen en la calle, sin ningún tipo de apoyo.

Por otro lado, se está produciendo en los centros una alarma social ante las reagrupaciones. Los menores no son informados y se les pilla "por sorpresa». Ocurre que los menores «huyen» a otras ciudades. De esta forma, menores tutelados por Cataluña, ante la amenaza de la repatriación, están desplazándose al País Vasco, Cantabria, Asturias y Galicia. Para un sistema de protección regionalista, esta movilidad plantea un problema, ya que no existen mecanismos flexibles adaptados a la movilidad de estos jóvenes. Lo que, a nuestros ojos de analistas, son estrategias de resistencia, son vistas con recelo por parte de los servicios sociales. Entendemos la enorme inversión de esfuerzo de los profesionales y la frustración ante los procesos de educación interrumpidos. Nos cuesta más entender una perspectiva que analiza la situación criminalizando a los menores como sujetos que «abusan» de los sistemas de protección.

La desprotección provocada por las reagrupaciones debe ser también analizada desde la perspectiva transnacional. Hemos señalado que la doble condición entre menores y extranjeros es lo que configura el tratamiento a los menores no acompañados, pero esto no ocurre sólo en España, sino también en Marruecos. No podemos olvidar que, tras la promulgación de la Ley no 02-03 relativa a la entrada y residencia de extranjeros en Marruecos, a la emigración e inmigración irregulares, de 20 de noviembre de 2003 (promovida por la UE y botón de muestra del desplazamiento de la frontera sur de Europa), un menor de dieciocho años que haya emigrado de manera irregular y sea devuelto a Marruecos está cometiendo una infracción, por lo que puede ser sanciona$\mathrm{do}^{15}$. Esto hace más compleja la reagrupación familiar del menor, ya que el derecho a vivir en familia reconocido en la Convención de Derechos de la Infancia y en el que se basa la reagrupación familiar puede ser «sancionable» por la legislación estatal marroquí, en lo que es una evidente contradicción entre leyes internacionales y nacionales. Por lo tanto, queda de manifiesto que el control de los flujos migratorios y de la migración irregular es en Marruecos una prioridad frente al respeto a los derechos de la infancia. Y el máximo exponente de esta contradicción es el trato que reciben por parte de las autoridades marroquíes los menores de origen subsahariano (demandantes de asilo, refugiados, acompañados por sus familias o solos), cuyo maltrato por parte de las autoridades marroquíes es manifiesto en las expulsiones de que son objeto y en la falta de reconocimiento de un estatuto de protección como menores.

Es decir, en el campo migratorio, por lo que se refiere al territorio que se extiende entre España y Marruecos, el Estado marroquí defenderá ante el espa-

15. Según el trabajo de campo, según el aeropuerto al que el menor llegue, recibirá un trato u otro. Al 100\% de los menores que llegan a Casablanca, se les aplica la Ley no $02-03$, sin embargo, a los menores que llegan a Tanger, no se les aplica. 
ñol la importancia de asegurar la protección y la tutela de los menores marroquíes migrantes en sus negociaciones bilaterales. Se defiende así la legislación de protección de la infancia a los menores en situación de desamparo, con independencia de su nacionalidad. Sin embargo, Marruecos discrimina a los menores procedentes del África Subsahariana y los maltrata, ante la incapacidad de reconocerlos como menores sujetos de protección. La misma dinámica de maltrato se produce en México con los menores centroamericanos, que son repatriados en setenta y dos horas. México y Marruecos, como países de tránsito hacia EEUU y Europa desempeñan un papel represor de los migrantes procedentes del sur (Centroamérica y África del Oeste), y es en un sujeto como los menores donde esta represión de hace más evidente, a pesar de que ambos países (México y Marruecos) son firmantes de la Convención de Derechos de la Infancia. Por lo tanto, las dinámicas de exclusión son también transnacionales, así como la intervención de los movimientos sociales, tanto en sus denuncias cómo en sus acciones.

Para terminar la aproximación a las repatriaciones, tenemos que desarrollar los instrumentos que España quiere poner en marcha en Marruecos para la aplicación del citado acuerdo bilateral firmado en marzo del 2007. Estos mecanismos utilizan la cooperación al desarrollo como vía de obtención de recursos y de implantación en Marruecos, pero pervierten el propio sentido de la cooperación, al esconder un objetivo contrario al propio desarrollo de los beneficiarios, en este caso, los menores migrantes. La cooperación al desarrollo es la cara amable y la antesala de una política de control de flujos migratorios. Pocas organizaciones no gubernamentales de desarrollo (ONGD) han realizado un análisis crítico de estos mecanismos. Sólo Human Rights Watch (HRW), en una carta enviada al presidente del gobierno en enero de 2007, le insta a "que incorpore en el futuro un acuerdo de readmisión con todas las garantías legales pertinentes de acuerdo a la legislación internacional y española aplicable».

Se refiere, principalmente, a dos proyectos centrados en la reagrupación de menores a Marruecos y financiados por la Comisión Europea. El primero llevado a cabo por la Consejería de Inmigración de la Comunidad de Madrid, financiado por el programa AENEAS y ejecutado por las asociaciones PAIDEIA y Entraide National. Dicho proyecto construirá dos centros para repatriar menores con menos de quince años, uno en Tánger y otro en Marrakech, por una cuantía de tres millones de euros. Por otro lado, la Generalitat de Cataluña, también financiado por el programa AENEAS, pondrá en marcha un programa de repatriación voluntaria de menores desde Cataluña hasta Tánger, por una cuantía de dos millones de euros. Es pronto para hacer una valoración de ambos programas. Sin embargo, llama la atención (y es significativo) que entre ambos programas no exista ningún mecanismo de coordinación real, a pesar de trabajar en el mismo territorio, con la misma población, con contrapartes similares y con el mismo financiador. Parece que responden a los intereses de las comunidades autónomas para crear mecanismos regionales que, de alguna forma, «adviertan» a los menores de la amenaza real de las repatriaciones. 
En todo caso, estos programas, con una perspectiva y una capacidad de intervención regional (sólo podrán ser repatriados menores que estén en los sistemas de protección de Madrid o de Cataluña, respectivamente) están incitando a la movilidad de estos menores, que, con cambiar de comunidad autónoma, pueden obviar la repatriación. Ocurre que en la Comunidad de Madrid, y gracias a toda una movilización de distintas organizaciones sociales, los jueces están declarando ilegales estas repatriaciones. Estas sentencias evidencian una mala práctica administrativa, que pone en entredicho el propio funcionamiento de los sistemas de protección. En Cataluña, los menores se fugan una vez que, desde los centros, se les comunica la repatriación y eso sucede a pesar de que no se da una notificación como tal y la posibilidad de poder recurrir dicha decisión administrativa mediante un abogado, que sería lo ajustado a derecho.

Los jóvenes conocen que esta política tiene como objetivo, por decirlo llanamente, "quitárselos de en medio». Así, se producen todo tipo de situaciones absurdas, como menores que se esconden por la noche en el centro y no duermen en su cama para evitar la repatriación por si la policía viene por ellos, menores que duermen en la calle y menores que huyen a otra comunidad autónoma o que buscan otras redes de apoyo alternativas a los centros de protección.

\section{A modo de conclusión}

Entendemos que promover las repatriaciones como forma de intervención social en este contexto migratorio obedece más a una lógica de control de flujos migratorios que a una lógica de protección de la infancia y menos de cooperación al desarrollo. Es, sobre todo, una ilustración del modo en que el Estado receptor interviene transnacionalmente a través de acuerdos bilaterales y programas de desarrollo para, a través de la reconceptualización de joven como dependiente de su familia biológica en origen, eludir su obligación normativa para con los menores en su territorio. La inclusión de estos menores en su capacidad agentiva, que redefine distancias y vínculos familiares desde una nueva situación del joven postcolonial, es vital para contraponer la retórica de la dependencia transnacional como base de la definición de los menores y, sobre todo, de negarles lo que ellos han venido a buscar: espacios de desarrollo personal y familiar.

La creación de centros para repatriar menores no son proyectos contextualizados, en cuanto que no cuentan con un análisis de las causas estructurales que condicionan la migración multicausal de estos menores. Como señala la psiquiatra marroquí Bargach (2008), un proyecto contextualizado es un requisito indispensable para todo interviniente en procesos sociales que involucran seres humanos altamente vulnerables. Se trata de establecer con rigor el estudio y la comprensión de estos fenómenos, así como elaborar una metodología de intervención efectiva y sensible a partir de dichos contextos. Tanto es así, que el interviniente que no contemple el fenómeno en su globalidad y en su complejidad, corre el riesgo de incurrir en generar 
«soluciones» o respuestas mutilantes e incluso perversas, es decir, contrarias a los fines propuestos.

La migración de estos menores pone de relieve, según Bargach, unas familias carentes de instrumentos para realizar el proceso de socialización de los jóvenes y estigmatizadas por los poderes públicos como «familias desestructuradas». Unos menores privados del derecho fundamental a saberse protegidos y un estado que delega las cuestiones fundamentales relacionadas con la intervención social a organizaciones no gubernamentales o supragubernamentales. Estos colectivos de menores potenciales migrantes son «invisibles» para los servicios sociales de su propio país. La emigración se convierte, como esperamos haber mostrado, en una manera de "protestar», de «rebelarse» ante la situación de marginación y olvido que sufren. La creación de estos centros será una forma de confirmarles en su imaginario que «tienes que emigrar para existir, tienes que emigrar para que tengas en tu propio país derechos que nunca tuviste antes de emigrar»y, por lo tanto, una forma de «propiciar la propia migración de otros menores que estén en Marruecos». Este mensaje viene a consolidar el imaginario colectivo de la migración como forma de promoción social, lo verifica y lo referza.

La pregunta final es qué ponen de manifiesto los menores migrantes. Centrándonos en los menores de origen marroquí, podemos señalar el revulsivo social que esta migración precoz genera, cristalizada en indignación por parte de las instituciones estatales (que la percibían como una migración de segunda categoría hasta que los proyectos de repatriación de menores empezaron a llenar las arcas de dichas entidades públicas) o compasión desde el mundo asociativo (que mantiene dicha percepción victimista de los menores o criminalizadora de sus familias). Estos jóvenes invierten el orden social y asumen un rol que no les corresponde. Ponen de relieve una creciente fractura social, no sólo medible con indicadores socioeconómicos. Una fractura social que tiene que ver con la quiebra de la familia, la escuela y la propia sociedad en la socialización de estos nuevos migrantes en un mundo globalizado.

\section{Referencias bibliográficas}

ARCE, Elena (2006). «Menores extranjeros no acompañados». En: LÁZARO GONZÁLEZ, Isabel y CULEBRAS LLANA, Irene. Nuevos retos que plantean los menores extranjeros al Derecho. IV Jornadas sobre Derechos de los Menores. Madrid: Publicaciones de la Universidad Pontificia de Comillas.

BARGACH, Amina (2008). I Jornadas Internacionales de Educación Intercultural, VI Jornadas de Diagnóstico y Orientacion de la Educacion Intercultural. La integración del menor migrante sin referente adulto en el país receptor: un reto universal para la educación intercultural. Jaén, 21, 22 y 23 de febrero.

Basch, Linda; Glick SChiller, Nina y Szanton Blanc, Cristina (1994). Nations Unbound. Transnational Projects. Postcolonial predicaments and deterritorialized nations-states. Pensilvania: Gordon and Breach Science Publishers.

FeiXa, Carles (1996). «Antropología de las edades». En: Prat, Joan y MarTíneZ, Ángel (eds.). Ensayos de Antropología Cultural. Barcelona: Ariel Antropología. 
- (1999). De jóvenes, bandas y tribus. Barcelona: Ariel.

Giménez Romero, Carlos y SuÁrez NaVAZ, Liliana (2001). Menores no acompañados que han entrado en territorio español sin representación legal. Informe de investigación (3 volúmenes).

JimÉNEZ Álvarez, Mercedes (2003). Buscarse la vida: Análisis transnacional de los procesos migratorios de los menores marroquies en Andalucía. Madrid: Fundación Santa María.

- (2006). «Menores inmigrantes o los vulnerables de la globalización». En: CHECA Olmos, F.; Arjona, A. y Checa Olmos, J.C. Menores tras la frontera. Barcelona: Icaria Antrazyt.

LE GALL, Josiane (2005). «Familles transnationales: bilan des recherches et nouvelles perspectives». Diversité Urbaine, vol. 5 (1).

MONTEROS, Silvina (2009) «La construcción social de un sujeto migratorio: los menores migrantes marroquíes no acompañados». En: JiménEZ A. Menores migrantes sin referentes familiares. Jaén: Universidad de Jaén.

OrellanA, M.F.; ThOrne, B.; CheE, A. y LAM, W.S.E. (2001). «Transnational childhoods: the participation of children in processes of family migration». Social Problems, vol. 48 (4).

SuÁREZ NAVAZ, Liliana (2004a). «Niños entre fronteras: Migración de menores no acompañados en el Mediterráneo Occidental». Migración y Desarrollo, Abril 2004, vol. 1

- (2004b). Rebordering the Mediterraneam: Borders and Citizenship in Southern Europe. Oxford: Berghahn Books.

- (2006). «Un nuevo actor migratorio: Jóvenes, rutas y ritos juveniles transnacionales». En: Checa Olmos, F.; ArjonA, A. y Checa Olmos, J.C.: Menores tras la frontera. Otra migración que aguarda. Barcelona: Icaria Antrazyt.

- (2007). «La perspectiva transnacional en los estudios migratorios: Génesis, derroteros y surcos metodológicos». En: LACOMBA, Joan et al. Migraciones en España. Una panorámica actual. Barcelona: Bellaterra

WhITEHEAD, Ann y HASHIM, Imad (2005): Children and Migration. Background Paper for DFID Migration Team. Centre on Migration, Globalisation and Poverty. Universidad de Sussex. Brighton. 